\title{
Symbolism in Religion: Ricoeurian Hermeneutics and Filipino Philosophy of Religion
}

Allan Cacho

\section{Symbols and Religious Experience}

I

$\mathrm{n}$ the study of the Filipino thoughts on religion, there are two important features of religion to consider in order to formulate a method that is suitable for the study of Filipino philosophy of religion. First, man experiences an encounter with the sacred, and this is called a religious experience. And this causes him to believe or to assent, and specifically, this is called faith. And second, symbols are used in expressing religious experience.

Man has various experiences. Parents experience joy as they hold in their arms their newborn baby. One experiences grief when a beloved has died. A man experiences the feeling of being in love with a beautiful girl. And he also experiences the feeling of being hurt when the girl turns down his love for her. Among these varied human experiences are the experiences of being mystified by the beauty of creation, of being grateful for surviving a dreadful disease like cancer, and of being at a loss in comprehending the love of God. These experiences signify the religious encounter, which is an encounter with the Divine. Secondly, the religious experience is expressed through rituals, myths, traditions and other symbolisms. Thus, religion employs a great number of symbols in conveying the religious experience. Considering this remark, it is no wonder that Filipinos have numerous religious symbols. This is due to the integratedness of religion in the everyday life of a Filipino. ${ }^{1} \mathrm{O}$ ne can readily observe these various Filipino religious traditions. Among these are the veneration of saints, the use of religious articles, and the various prayer devotions. In order to understand Filipino thoughts about religion, there is a need to understand the religious symbols that surround Filipino religiosity.

Considering these important factors, the use of a hermeneutical method is necessary in the study of Filipino philosophy of religion. There is a need for hermeneutics in order to interpret and understand the dynamics of Filipino religiosity and to discover the various symbolisms in relation with Filipino religiosity. Thus, it is significant to take into account that the hermeneutical method must be able to consider the religious experiences of the

${ }^{1}$ Cf. Leonardo Mercado, Elements of Filipino Philosophy, (Tacloban City: Divine Word University, 1976), 160. 
Filipinos and the meaning of the religious symbolisms. Paul Ricoeur's method of phenomenological hermeneutics ${ }^{2}$ is appropriate for this kind of study since it gives great consideration to symbolisms.

\section{The Problem of Language in Philosophy of Religion}

In the middle of the development of his philosophical discourse on the philosophy of the will, Paul Ricoeur has admitted that he encounters problems in introducing the aspect of evil in the structures of the will. In his article entitled "From Existentialism to the Philosophy of Language," he confesses, "But at the same time, a secondary problem emerged, which tended afterwards to pass to the forefront of my inquiries. This was the problem of language. Why? Because in order to introduce the dimension of evil into the structure of the will, a fundamental change in the method of description itself was required." 3 In his previous works on the philosophy of the will, he employed what he calls existential phenomenology. 4 However, the issue of evil brought along new linguistic problems in his study of the will. In relating his thoughts on finitude and on guilt, he saw the need to deal with symbols in religious language which is an indirect approach to the problem. Ricoeur clarifies, ". . . but we speak of evil by means of metaphors such as estrangement, errance, burden, and bondage. Moreover, these primary symbols do not occur unless they are embedded within the intricate narratives of myth..." 5 Taking this into account, he develops a hermeneutical method that deals with symbols in order to achieve his objectives. He takes a detour by studying the problem of language in the hermeneutical tradition. With these, one readily recognizes the importance of Ricoeur's hermeneutics in the study of Filipino philosophy of religion. Embedded in the different Filipino religious practices, such as devotion to the saints and belief in religious articles, are symbols that speak about Filipino thoughts on religion. Understanding these symbolisms are of utmost importance in any study of Filipino religious thought.

\section{The Phenomenological Hermeneutics of Symbols}

Religious experiences are expressed through symbols and these symbols are embedded in these practices. Furthermore, Ric-Zeus Angobung suggests in his thesis that, ". . . we need to look at religion from the inside: asking about the inner experiences of the believer, searching for the meanings

2 One should not confuse Ricoeur's phenomenological hermeneutics with Husserl's phenomenology. Although he adapted some tenets of Husserl's phenomenology into his own thought, Ricoeur's method is considered a post-structural hermeneutics. Cf. Kim Atkins, "Paul Ricoeur," in Intemet Engydopedia of Philosqphy, accessed July 23, 2004 < http:/ / www.iep.utm.edu>. 3 Paul Ricoeur, "From Existentialism to the Philosophy of Language," in Philosophy Today, v. 17/ 1-4 (1973), 89.

${ }^{4}$ Cf. Ibid

5 Ibid, 90. 


\section{SYMBOLISM IN RELIGION}

that underlie liturgical symbols, looking for interpretation to the words and sounds that we find." 6 Thus, it is important to study the religious symbols in order to understand the inner religious experiences of man and his thoughts on religion. Furthermore, the different religious practices are meaningful due to these symbols. As one may notice the study of symbol is a significant factor in the study of religious thoughts. Thus, it is of great importance to consider what a symbol is.

To begin with, a symbol does not have the quality of conceptual clarity and specificity. Rather, it has the characteristics of vagueness and ambiguity. However, the power of symbols lies in its vagueness. What it lacks in conceptual clarity is filled up by the power of its suggestiveness. Ricoeur points out, "If no concept can exhaust the requirement of further thinking borne by symbols, this idea signifies only that no given categorization can embrace all the semantic possibilities of a symbol." 7 Angobung reiterates this point, "It [symbol] is opaque inasmuch as upon notice of the symbol we do not actually grasp what its real meaning is, and so it is vague for us what it really intends to signify. . . . Because of this opacity, a symbol is rich, precisely because of the lack of its conceptual specificity. In its opacity, a symbol is seen to be a profound expression." 8 However, one wonders on how he is able to understand, and consequently, interpret symbols given its opacity, i.e., its conceptual vagueness and ambiguity. Furthermore, Ricoeur argues that a symbol is characterized as having both semantic and non-semantic dimensions. Ricoeur clearly shows this point:

. the concept "symbol" brings together two
dimensions, we might even say, two universe, of
discourse, one linguistic and the other of a non-linguistic
order. The linguistic character of symbols is attested to
by the fact that it is indeed possible to construct a
semantics of symbols, i.e., a theory that would account
for their structure in terms of meaning or signification.
Thus we can speak of the symbol as having double
meaning .... But the non-linguistic dimension is just
obvious as the linguistic one. ... a symbol always refers
its linguistic element to something else. 9

On the one hand, there is something in the symbols that can be subjected to linguistic analysis. On the other hand, there is also something that resists linguistics. Thus, a significant question that needs to be considered is drawn from these ambiguous characteristics of a symbol: "How can one

6 Ric-Zeus Excellency E. Angobung, Metaphor in Reigiaus Langrage A Study an Paul Ricaur(Manila: Faculty of Philosophy - University of Santo Tomas, 1995), 68.

7 Paul Ricoeur, Inteppretation Theary. Discarse and the Surplus of Meaning (Fort Worth: Texas Christian University Press, 1976), 57.

${ }^{8}$ Angobung, qpat, 53-54.

${ }^{9}$ Rico eur, Interpretation Theory, 54. 
understand and interpret symbols?" Ricoeur relates his theory of metaphor to provide clarifications with regard to this issue of understanding symbols.

For Ricoeur, metaphors should primarily be studied under the semantics of a sentence, rather than that of a word. He explains:

Metaphor has to do with semantics of the sentence before it concerns the semantics of a word. And since a metaphor only makes sense in an utterance, it is a phenomenon of predication, not denomination. When the poet speaks of "blue angels," or a "mantle of sorrow," he puts two terms ... in tension. And only the ensemble constitutes the metaphor. So we should not really speak of the metaphorical use of a word, but rather of the metaphorical utterance. The metaphor is the result of the tension between two terms in a metaphorical utterance. 10

Furthermore, it is important to note that Ricoeur considers a metaphor as a phenomenon of predication, and not, of denomination. For, he later capitalizes in this distinction in order to explain that the metaphorical tension is between two levels of interpretations and not of the two terms. And the interplay between these two levels explains the power of suggestiveness of a metaphor. Ricoeur describes the interplay of the levels, "The metaphorical interpretation presupposes a literal interpretation which self-destructs in a significant contradiction. It is this process of self-destruction or transformation which imposes a sort of twist on the words, an extension of meaning thanks to which we can make sense where a literal interpretation would literally nonsensical." 11 Ricoeur applies the tension theory of metaphor into symbols. However, he talks about signification in the case of symbols. ${ }^{12}$ Thus, Ricoeur defines symbol as, ". . . any structure of signification in which a direct, primary, literal meaning designates, in addition, another meaning which is indirect, secondary and figurative and which can be apprehended only through the first." 13 One should keep in mind that Ricoeur applied only the tension theory of metaphor to explain the excess of signification in a symbol. He puts into tension the excess of signification and the literal signification which is only possible by also placing two interpretations into a tension. Ricoeur explains the two interpretations:

Only for an interpretation are there two levels of signification since it is the recognition of the literal meaning that allows us to see that a symbol still contains

\footnotetext{
10 Ibid., 49-50.

11 Ibid., 50.

12 Cf. Ibid., 55-56.

13 Paul Ricoeur, The Conflict of Interpretation: Essays in Hermeneutics (Evanston: Northwestern University Press, 1974), 12.
} 
more meaning. This surplus of meaning is the residue of the literal interpretation. Y et for the one who participates in the symbolic signification there are really not two significations, one literal and the other symbolic, but rather a single movement, which transfers him from one level to the other and which assimilates him to the second signification by means of, or through the literal one. ${ }^{14}$

Clearly, just like in a metaphor, the literal interpretation leads to the conclusion that there is a surplus of meaning in a symbol. However, the distinction made by the literal interpretation is dissolved in the interpretation of symbolic signification. Then, Ricoeur describes the importance of this interpretation:

Symbolic signification, therefore, is so constituted that we can only attain the secondary signification by way of the primary signification, where this primary signification is the sole means of access to the surplus of meaning. The primary signification gives the secondary signification, in effect, as the meaning of meaning. ${ }^{15}$

Thus, in the interpretation of a symbol, the primary signification, which is the literal meaning, is needed in the understanding of the secondary signification of the symbol. However, as noted earlier, symbols have nonlinguistic dimension, and as Ricoeur describes it, "For something in a symbol does not respond to a metaphor and, because of this fact, resists any linguistic, semantic or logical transcription." 16 Again, by way of contrast, the theory of metaphor proves to be valuable.

At the onset of his discussion of the non-semantic moment of a symbol, Ricoeur states the main reason for the resistance of a symbol from a linguistic interpretation, "This opacity of a symbol is related to the rootedness of symbols in areas of our experience . ..."17 And he discusses three human experiences in which symbols are "bounded." These three are the psychoanalysis, poetics and religiosity. Since the current study is on religious thoughts, the researcher focuses on the rootedness of symbols in the religious experience in order to explain that a symbol is bounded to experience. Ricoeur argues that, "symbols are bound within the sacred universe ...." 18 He starts his argument by a warning:

... Rudolf $\mathrm{O}$ tto ... strongly emphasized the appearance of the Sacred as power, strength, efficacity. . . . it is

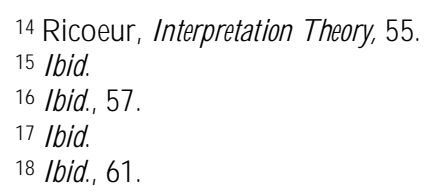


valuable in that it helps us to be on guard against all attempts to reduce mythology linguistically. We are warned from the very beginning that we are here crossing the threshold of an experience that does not allow itself to be completely inscribed within the categories of logos or proclamation and its transmission or interpretation. ${ }^{19}$

The Sacred, although there have been manifestations, or hierophany as Eliade describes it, eludes to be totally under language and thus, linguistic analysis. This evasion from the total grasp of language is due to the preverbal character of such experiences and this is clearly seen in notions of sacred place and sacred time, which he relates to Kantian concepts. ${ }^{20}$ Clearly, symbols are unbound with respect to language due to its boundness, first and foremost, to the cosmos. Ricoeur, furthermore, explains this point by discussing the bond between myth and ritual, "The bond between myth and ritual attest in another way to this non-linguistic dimension of the Sacred. It functions as logic of correspondences, which characterize the sacred universe and indicate the specificity of homo religiosus' vision of the world. Such ties occur at the very level of the very elements of the natural world . ..." 21 Thus, religious symbols are bound in the cosmos and, therefore, in human experience because, as logic of correspondence, they point to the sacred universe and also signify man's religious experience. By explaining the character of a symbol as logic of correspondence, Ricoeur was not only able to point out the primacy of the non-semantic moment but he has also explained the movement of the nonsemantic to the semantic of a symbol. He explains in detail:

Such is the logic of correspondences, which binds discourse in the universe of the Sacred. We might even say that it is always by means of discourse that this logic manifests itself .... Even more, symbolism only works when its structure is interpreted. In this sense a minimal hermeneutic is required for the functioning of any symbolism. But this linguistic articulation does not suppress what I have called the adherence to symbolism characteristic of the sacred universe, rather it presupposes it. . . . The sacredness of nature reveals itself in saying itself symbolically. The revealing grounds the saying, not the reverse. ${ }^{22}$

Thus, the non-semantic moment, which resists interpretation, leads paradoxically to the semantic, which subjects it to interpretation. However, it

19 Ibid., 60.

20 Cf. Ibid., 61.

21 Ibid., 61.

22 Ibid., 62-63. 


\section{SYMBOLISM IN RELIGION}

must be noted that the non-semantic moment has the primacy over the semantic.

It seems that the above discussions on the semantic moment and the non-semantic moment only leads to interpretation of the primary signification, which is the literal, and a minimal interpretation of symbols, respectively. However, Ricoeur used the non-semantic moment of a symbol to widen the application of his theory of signification which is based on his insights on metaphors. At the onset of his discussion on metaphors and symbols, he aims, "But if the theory of metaphor can serve as a preparatory analysis leading up to the theory of the symbol, in return the theory of symbol will allow us to extend our theory of signification by allowing us to include within it, not only verbal double-meaning, but non-verbal double-meaning as well." 23 Thus, the thin line that distinguishes a symbol from a metaphor diminishes. One considers a symbol as metaphoric and a metaphor as symbolic. Ricoeur outlines three aspect of the metaphorical functioning of symbolisms. However, I will combine the first two aspects. Thus, the discussion is focused on symbolisms as a hierarchical network, and as a model.

The first two aspects of metaphorical functioning that Ricoeur considers can be summarized to be a hierarchical network. A metaphor, as an event of discourse, is only conceived at the moment of invention. Ricoeur points out, "In fact, by calling metaphor a semantic innovation, we emphasize the fact that it only exists in the moment of invention. Lacking any status in established language, a metaphor is in the strong sense of the word, an event of discourse." 24 However, symbols, due to its boundness in the cosmos, receive a kind of stability which makes them enduring. How can this apparent contradiction which moves in two opposite directions be resolved? According to Ricoeur: "Metaphorical functioning would be completely inadequate as a way of expressing the different temporality of symbols, what we might call their insistence, if metaphors did not save themselves from complete evanescence by means of a whole array of intersignifications." 25 This aspect rescues metaphors from their fleeting moments while explains the transformations of symbols through time. Furthermore, the metaphorical functioning does not only link the metaphors, but "presents an original hierarchical order." Ricoeur explains, ". . . certain metaphors are so radical that they seem to haunt all human discourse. These metaphors . . . become indistinguishable from the symbolic paradigm Eliade studies in his Patterns in Comparative Religion." 26 Thus, the metaphorical functioning does not only call for a network of signification, but it calls for an ordered network of metaphors. Furthermore, in a certain network, there is what Ricoeur calls a "symbolic experience" which, ". . . calls for a work of meaning from metaphor, a work which it partially provides through its organizational network and its

\footnotetext{
23 Ricoeur, Interpretation T heory, 46.

24 Ibid., 64.

25 Ibid.

26 Ibid., 65.
} 
hierarchical levels." 27 This symbolic experience holds the other metaphors in its network and provides a venue for other metaphors to be articulated. Ricoeur points this out, "Everything indicates that symbol systems constitute a reservoir of meaning whose metaphoric potential is yet to be spoken." 28 And this symbolic experience has the characteristic of elucidating other metaphors because it signifies certain fundamental human experiences.

The third aspect of metaphorical function is that of a model. Ricoeur enumerates three kinds of models: the scale model, the analogical model and the theoretical model. Ricoeur focuses his discussion on theoretical models because these models are the real models, from an epistemological perspective. Theoretical models are imaginary constructed objects which are more accessible to description and should correspond to the properties of a more complex domain of reality. Ricoeur shows that metaphorical function in literature functions in a similar way to a model in scientific language. He has done this by relating the two notions of heuristic fiction and the redescription that occurs through the transference of this fiction to reality. ${ }^{29}$ However, the important aspect to note on Ricoeur's discussion about theoretical models is its application to metaphorical function. Ricoeur discusses in detail:

Considered in terms of its referential bearing, poetic language has in common with scientific language that it only reaches reality through a detour that serves to deny our ordinary vision and the language we normally use to describe it. In doing this both poetic and scientific language aim at a reality more real than appearances. ... The suspension of the referential function of the first degree affects ordinary language to the benefit of a second degree reference, which is attached precisely to the fictive dimension revealed by the theory of models. In the same way that the literal sense has to be left behind so that the metaphorical sense can emerge, so the literal reference must collapse so that the heuristic fiction can work its redescription of reality. ${ }^{30}$

This quotation discusses a very important thing in interpretation. Metaphorical function calls for the interpreter "to see reality as . ..." Symbols and metaphors create a world of their own. However, this does not mean that they do not correspond, or to be more specific, have no referentiality to reality. The scientific theory of model demonstrates that, as a heuristic fiction, a model was able to arrive at a more accurate description of reality since it goes beyond mere appearances. Thus, metaphoric function, when the literal sense and reference are suspended, has the ability to arrive at redescription of the

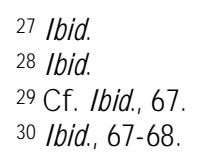




\section{0}

\section{SYMBOLISM IN RELIGION}

complex reality. With the discussion of the theory of symbols, one can conclude that there are three moments in the Ricoeur's hermeneutics of symbols: namely, the semantic; the non-semantic; and lastly, the metaphorical.

\section{Conclusion}

A quick survey of the study of Filipino philosophy of religion reveals the problem of language in the study since the thoughts that are derived from religious experience are mostly expressed in symbolisms. This is not surprising since these symbolisms have the ability for redescription of the complex reality of the encounter with the Divine, concepts, useful as they are, still fail to express adequately. The power of symbolism lies in its ambiguous character that opens up for redescription. However, the ambiguity of symbolism is the very challenge that it poses. It is easy to wander off in the study of symbolism and to force one's own interpretation of the symbols.

Paul Ricoeur's theory of symbols offers a possible way of understanding the dynamics of symbolism and, thus, gives the opportunity to interpret symbolisms without the problems of wandering off and forcing one's interpretation. The semantic and non-semantic moments ground the interpretation of symbolisms. Firstly, the semantic moment which looks into the literal sense of the symbolism sets a limit in interpretation since it marks off the boundary of the world of the symbol. Secondly, the non-semantic moment which speaks about the rootedness of symbolisms in the human experience provides the milieu for interpretation. Religious symbolisms make sense if one considers the religious experience which it expresses and from which it is derived. These two moments provide a solid ground in allowing the meaning of the symbolisms to emerge and be understood. Moreover, they guide the interpretation into the last moment of the hermeneutics of symbolisms, which is the metaphorical. The metaphorical function of symbols makes possible to explore the ambiguity of symbolisms and to open the world of the symbol for the redescription of the complex reality of religious experience. In this regard, the hermeneutics of Paul Ricoeur with its focus on symbolisms is an appropriate methodology for the study of Filipino philosophy of religion.

School of Theology, U niversity of St. Thomas (H ouston), U nited States

\section{References Cited}

Angobung, Ric-Zeus Excellency E., M etaphor in Religious L anguage: A Study on Paul Riceur (Manila: Faculty of Philosophy - University of Santo Tomas, 1995).

Atkins, Kim, "Paul Ricoeur," in Internet E ncydopedia of Philosophy, accessed July 23, 2004 <http:/ / www.iep.utm.edu>.

Mercado, Leonardo, E lements of F ilipino Philosophy (Tacloban City: D ivine Word University, 1976). 


\section{A. $\mathrm{CACHO} 131$}

Ricoeur, Paul, Figuring the Sacred: Religion, N arrative and Imagination (Minneapolis: Fortress Press, 1995).

, "From Existentialism to the Philosophy of Language," in Philosophy Today, v. 17/ 1-4 (1973), 88 - 96.

, H ermeneutics and H uman Scienoes: E ssays on L anguage, A ction and Interpretation (Cambridge: Cambridge University Press, 1981).

, Interpretation Theory: D iscourse and the Surplus of Meaning (Fort Worth: Texas Christian University Press, 1976).

, The Conflict of Interpretation: E ssays in $\mathrm{H}$ ermeneutics (Evanston: Northwestern University Press, 1974).

, "The Task of Hermeneutics," in Philosophy Today, v. 17/ 1-4 (1973), 112-128. 